\title{
THE URINARY EXCRETION AND BIOLOGIC DECAY PERIODS OF RADIOMERCURY LABELING A MERCURIAL DIURETIC IN NORMAL AND DISEASED MAN ${ }^{1}$
}

\author{
BY GEORGE BURCH, THORPE RAY, SAM THREEFOOT, FRANK J. KELLY,² \\ AND ARTHUR SVEDBERG
}

(From the Department of Medicine, Tulane University School of Medicine and Charity Hospital of Louisiana at New Orleans)

(Submitted for publication March 23, 1950; accepted, May 29, 1950)

In previous studies (1) some aspects of the mechanisms of renal excretion of radiomercury ${ }^{3}$ labeling an organic mercurial diuretic (Mercuhydrin ${ }^{4}$ ) were observed in acute experiments in which renal venous blood and pelvic urine were obtained by means of catheters in a few subjects. The present observations are concerned with the rate of urinary excretion of the radiomercury of this diuretic in a larger number of subjects over a longer period of time. The percentage of injected radiomercury which was excreted in the urine, the time relationships of the diuretic effects and the urinary excretion of the mercury, the biologic decay rates of the isotopes, as well as other physiologic phenomena were determined from these experiments. Because of the extensive use of mercurial diuretics in clinical medicine and the problems of toxicity, the biologic decay rates are of importance.

\section{MATERIALS AND METHODS}

Eighty-three hospitalized subjects were studied. The diuretic was administered intravenously and intramuscularly to normal human subjects and to subjects with congestive heart failure. Table I shows the route of ad-

\footnotetext{
1 Aided by grants from the Life Insurance Medical Research Fund, a War Department Grant No. W-49-007MD-389, the Mrs. E. J. Caire Fund for Research in Heart Disease and the National Heart Institute.

2 Life Insurance Medical Research Fund Postdoctorate Fellow (1948-1949), Department of Medicine, Tulane University School of Medicine and Charity Hospital of Louisiana, New Orleans.

${ }^{3}$ Radioactive mercury $\left(\mathrm{Hg}^{203,}{ }^{205}\right)$ was obtained from the Isotopes Division of the Oak Ridge National Laboratory.

4 The sodium salt of methoxyoximercuripropylsuccinylurea with theophylline, prepared with radiomercury in this laboratory by Messrs. Harold Krahnke, Darwin Kaestner and Edwin Sprengler through the courtesy of Dr. H. L. Daiell, Director of Research, of Lakeside Laboratories, Milwaukee.
}

ministration employed for the subjects of each clinical group. The control subjects were free from cardiovascular and renal diseases; most of them had primarily such illnesses as psychoneuroses or peptic ulcer or were convalescing from a respiratory infection. The subjects who were made to sweat had psychoneurosis or inactive peptic ulcer. They were placed in a hot and humid room ( $\approx 45^{\circ} \mathrm{C}$. and 95 per cent relative humidity) for periods varying from 20 to 90 minutes, the sweating procedure beginning from 0 to 90 minutes after injection of the diuretic. The patients with chronic congestive heart failure included groups in varying stages and degrees of failure with and without edema. The group of miscellaneous subjects had renal disease (subacute or chronic active glomerulonephritis) or hepatic cirrhosis.

One to $3 \mathrm{cc}$. of the mercurial diuretic, each containing $39 \mathrm{mg}$. of mercury, were administered by routes indicated in Table $I$. The quantity of radioactive material administered varied from $100 \mu \mathrm{c}$. in the earlier experiments to $10 \mu \mathrm{c}$. in the later ones.

Each voided specimen of urine was collected separately and its volume and radioactivity were determined (2). Samples of plasma or serum were obtained at varying intervals of time. Collections of urine and blood were made until there was no detectable radioactivity, i.e., until the counts reached background level.

Expression of data. The radiomercury in each fluid studied was expressed as counts per minute per cc. The time-course of the cumulative excretion of radiomercury was expressed as a percentage of the total counts excreted in the urine for all subjects in whom collections of

TABLE I

Route of administration of radiomercury injected for various clinical groups

\begin{tabular}{|c|c|c|c|}
\hline \multirow{2}{*}{ Subject groups } & \multicolumn{2}{|c|}{ Route of administration } & \multirow{2}{*}{ Total } \\
\hline & I. V. & I. $\mathbf{M}$. & \\
\hline $\begin{array}{l}\text { Control } \\
\text { Sweated } \\
\text { Congestive heart failure } \\
\text { Miscellaneous }\end{array}$ & $\begin{array}{c}\text { No. of } \\
\text { subjects } \\
35 \\
8 \\
20 \\
5\end{array}$ & $\begin{array}{c}\text { No. of } \\
\text { subjects } \\
8 \\
0 \\
7 \\
0\end{array}$ & $\begin{array}{c}\text { No. of } \\
\text { subjects } \\
43 \\
8 \\
27 \\
5\end{array}$ \\
\hline Total & 68 & 15 & 83 \\
\hline
\end{tabular}


all urinary output during the study were made. A mean curve was obtained for each group of subjects.

Since 88 per cent of the injected mercury was recovered for the control subjects, 100 per cent of the recovered mercury represents $8,800,000 \mathrm{CPM}$ (counts per minute) or $68.64 \mathrm{mg}$. in a dose of $2 \mathrm{cc}$. This relationship is approximately the same for the subjects with congestive heart failure.

In the early studies errors existed due to loss by volatilization of mercury from the preparations of urine made for counting. Data obtained after methods of circumventing these difficulties were devised permitted determination of the percentage of the total administered dose excreted in the urine of 12 subjects. Because of the extreme variation in the chemical nature of urine, the error due to volatilization was inconstant from subject to subject but remained relatively constant for all of the samples of any one subject. The temporal and percentile relationships are therefore satisfactory. The problem of volatilization and other special features peculiar to tracer studies with mercury are presented in detail elsewhere (3).

It should be emphasized that only the radiomercury of the mercurial diuretic was traced regardless of its chemical state; the latter was unknown at all times.

\section{RESULTS}

To simplify the presentation of the data, results are divided into: (1) biologic decay periods, (2) time-course of urinary excretion, and (3) rate of clearance of radiomercury by the kidneys.

(1) Biologic decay periods (Results are summarized in Table II)

(a) $C_{j}$ values. The mean $C_{\xi}$ values, determined graphically, for the control subjects were smaller than those for the subjects with chronic
TABLE III

Time required for concentration of mercury in the serum to reach background levels

\begin{tabular}{|c|c|c|c|c|c|c|c|}
\hline \multirow{2}{*}{ Group } & \multicolumn{6}{|c|}{ Time background reached } & \multirow{2}{*}{$\begin{array}{l}\text { Total } \\
\text { No. }\end{array}$} \\
\hline & \multicolumn{2}{|c|}{$\stackrel{18 \mathrm{t}}{24-30 \mathrm{hrs} .}$} & \multicolumn{2}{|c|}{$\begin{array}{c}2 \mathrm{nd} \\
24 \mathrm{hrs}\end{array}$} & \multicolumn{2}{|c|}{$\begin{array}{c}3 \mathrm{rd} \\
24 \mathrm{hrs} .\end{array}$} & \\
\hline $\begin{array}{l}\text { Control, I. V. } \\
\text { Control, I. M. } \\
\text { Control, I. V. } \\
\text { Sweated } \\
\text { CHF, I. V. } \\
\text { CHF, I. M. } \\
\text { Miscellaneous }\end{array}$ & $\begin{array}{r}\text { No. } \\
16 \\
4 \\
3 \\
\\
5 \\
3 \\
4\end{array}$ & $\begin{array}{l}\% \\
94 \\
80 \\
50 \\
\\
50 \\
60 \\
80\end{array}$ & $\begin{array}{c}\text { No. } \\
1 \\
1 \\
2 \\
3 \\
1 \\
1\end{array}$ & $\begin{array}{r}\% \\
6 \\
20 \\
33 \\
\\
30 \\
20 \\
20\end{array}$ & $\begin{array}{c}\text { No. } \\
0 \\
0 \\
1 \\
2 \\
1 \\
0\end{array}$ & $\begin{array}{r}\% \\
0 \\
0 \\
17 \\
\\
20 \\
20 \\
0\end{array}$ & $\begin{array}{r}17 \\
5 \\
6 \\
10 \\
5 \\
5\end{array}$ \\
\hline Total & 35 & 73 & 9 & 19 & 4 & 8 & 48 \\
\hline
\end{tabular}

congestive heart failure. $\mathrm{C}_{\frac{1}{3}}$ for radiomercury was slightly smaller, when the diuretic was administered intravenously than when administered intramuscularly, although there was overlapping of values.

Although $\mathrm{C}_{3}$ was previously described for radiosodium (4) and radiochlorine (5) as the time required for the concentration in the serum to reach half the concentration after equilibrium of distribution of the isotope had been reached, the radiomercury apparently reaches a steady state rather than equilibrium of distribution because of the rapid rate of excretion. However, in subjects with considerable impairment of renal function equilibrium of distribution was probably obtained.

(b) Time to reach background count. The time in hours required for the radiomercury in the plasma to reach a background count $\left(C_{b}\right)$ is

TABLE II

Biologic decay periods of radiomercury

\begin{tabular}{|c|c|c|c|c|c|c|c|}
\hline Group & $\begin{array}{l}\text { No. of } \\
\text { subjects }\end{array}$ & $\underset{C_{j}}{\text { Mean }}$ & $\underset{U_{1}^{*}}{\operatorname{Mean}}$ & $\begin{array}{l}\text { Mean } \\
\mathrm{UE}_{\mathbf{j}}\end{array}$ & $\underset{U_{b}}{\text { Mean }}$ & $\begin{array}{l}\text { Mean } \\
\mathrm{WE}_{\xi}\end{array}$ & $\underset{\text { recovery* }}{\text { Total }}$ \\
\hline Control, I. V. & 25 & $\begin{array}{c}\text { hrs. } \\
2.2 \\
(1.0-3.7)\end{array}$ & $\begin{array}{l}\text { hrs. } \\
2.3 \\
(1.5-4.5)\end{array}$ & $\begin{array}{c}\text { hrs. } \\
2.2 \\
(0.81-7.4)\end{array}$ & $\begin{array}{l}\text { hrs. } \\
27.2\end{array}$ & $\begin{array}{l}\text { hrs. } \\
4.8\end{array}$ & $\begin{array}{c}\text { Per cent } \\
88 \\
(80.4-95.5)\end{array}$ \\
\hline Control, I. M. & 5 & $\begin{array}{c}2.5 \\
(2.2-3.2)\end{array}$ & & $\begin{array}{c}4.1 \\
(2.4-7.8)\end{array}$ & 37.2 & 7.5 & \\
\hline Control Sweated, I. V. & 7 & & & $\begin{array}{c}2.1 \\
(0.9-2.4)\end{array}$ & 36.7 & 14.4 & \\
\hline Congestive heart failure, I.V. & 8 & $\begin{array}{c}4.0 \\
(2.2-7.0)\end{array}$ & & $\begin{array}{c}3.2 \\
(1.6-6.0)\end{array}$ & 43.9 & 14.6 & \\
\hline Congestive heart failure, I. M. & 6 & $\begin{array}{c}5.0 \\
(2.9-11.5)\end{array}$ & & $\begin{array}{c}4.6 \\
(3.1-6.4)\end{array}$ & 45.7 & 12.8 & \\
\hline
\end{tabular}

* For 12 control subjects in whom effects of volatilization did not offer difficulties (2). 
indicated in Table III for the various groups of subjects. Since the samples of serum were collected at six to 24 hour intervals after the first six hours of study, the $C_{b}$ values are not sharply demarcated (Table III).

The serum counts reached background within the first 24 hours in 94 per cent of the control subjects; in only one was there radiomercury in the serum on the second day when the diuretic was administered intravenously. When administration was intramuscular, approximately the same amount of time was required for background to be reached. Thermal sweating apparently did not alter the concentration-time course of the radiomercury in the serum, whereas chronic congestive heart failure tended to prolong the latter (Table III).

(c) $U_{\frac{1}{3}}$. A mean $U_{\frac{1}{3}}$ value, the time required for half of the injected radiomercury to be excreted in the urine, of 2.3 hours (range 1.5 to 4.5 hours) was obtained for the 12 control subjects (Table II). This $U_{\frac{1}{3}}$ value is almost the same as the $\mathrm{C}_{f}$ value of 2.2 hours for the same group, which is to be expected since almost all the radiomercury is excreted by way of the urine (6).

(d) $U E_{3}$. These values represent the time required for half the total radiomercury excreted in the urine to be eliminated by way of the urine and are summarized in Table II. As would be expected from the $U_{\xi}$ and $C_{\xi}$ values previously discussed, $\mathrm{UE}_{\boldsymbol{\xi}}$ was larger for subjects with chronic congestive heart failure than for the control subjects and larger for the intramuscular route of administration than for the intravenous (Table II).

(e) Time for urine to reach background, $U_{b}$. This parameter measures the time after injection when no more measurable radioactive mercury appears in the urine and is represented in Figure 1 by the time when the 100 per cent value was reached. The control subjects excreted "all" of the mercury more rapidly than did the subjects with congestive heart failure (Table II).

(f) $W E_{\frac{1}{3}}$. This parameter indicates the time required for half the total volume of urine containing measurable amounts of radiomercury to be excreted. These mean values as well as the $\mathrm{UE}_{\text {z }}$ values (Table II) were obtained from the curves shown in Figure 1. The $\mathrm{WE}_{\mathfrak{\xi}}$ values were larger for the subjects with chronic congestive heart fail-
PERCENTAGE EXCRETION OF RADIOMERCURY AND WATER
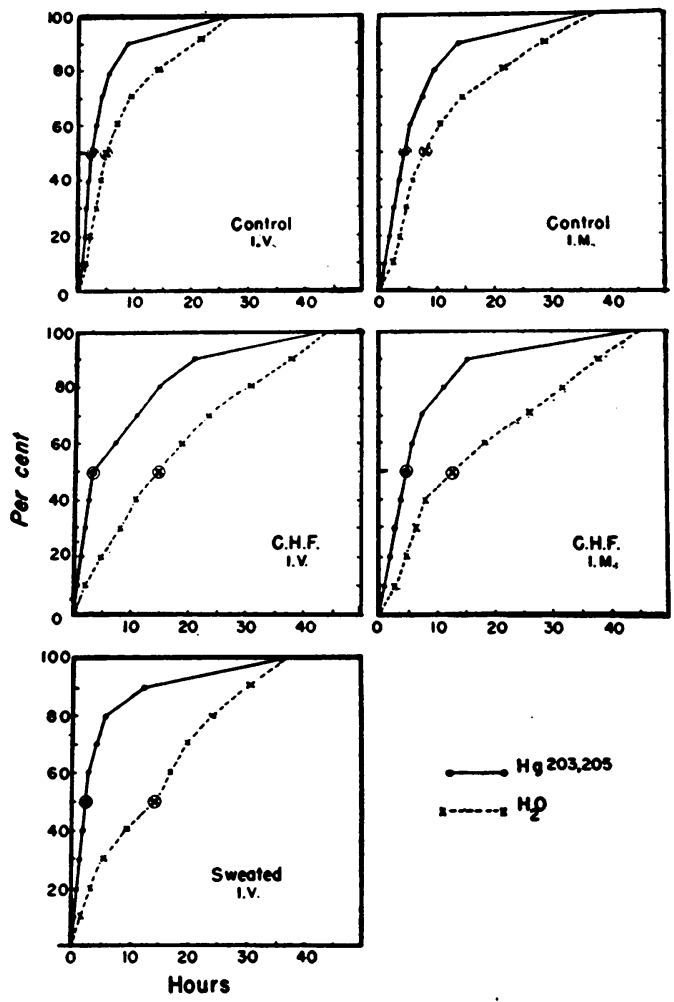

Fig. 1. The Mean Cumulative Output of RadiomerCURy aNd Water for Five Groups of Subjects

The 100 per cent value for radiomercury represents the total recovered mercury. The 100 per cent value for water output represents the total volume of urine excreted from the time of injection to the time when no more radioactivity was detectable in the urine. The curves may be expressed by the equation

$$
R_{t}=\sum_{\mathbf{s}-1}^{t} \times R_{\mathbf{s}},
$$

where $R=$ percentage excreted up to time $t$, where $s=$ any one unit of time, and where $t=$ time in hours.

ure and those who had sweated than for the control subjects.

Figure 1, which represents the cumulative urinary excretion of radiomercury and water, reveals a steeper slope of the curves of excretion of water during the initial period than the latter period for all groups of subjects. This is probably due to the diuretic effect of the preparation, which is most intense during the first 10 to 12 hours and begins to decline thereafter. Differences in duration of excretion of water in the groups shown in 
PERCENTAGE EXCRETION OF RADIOMERCURY AND WATER

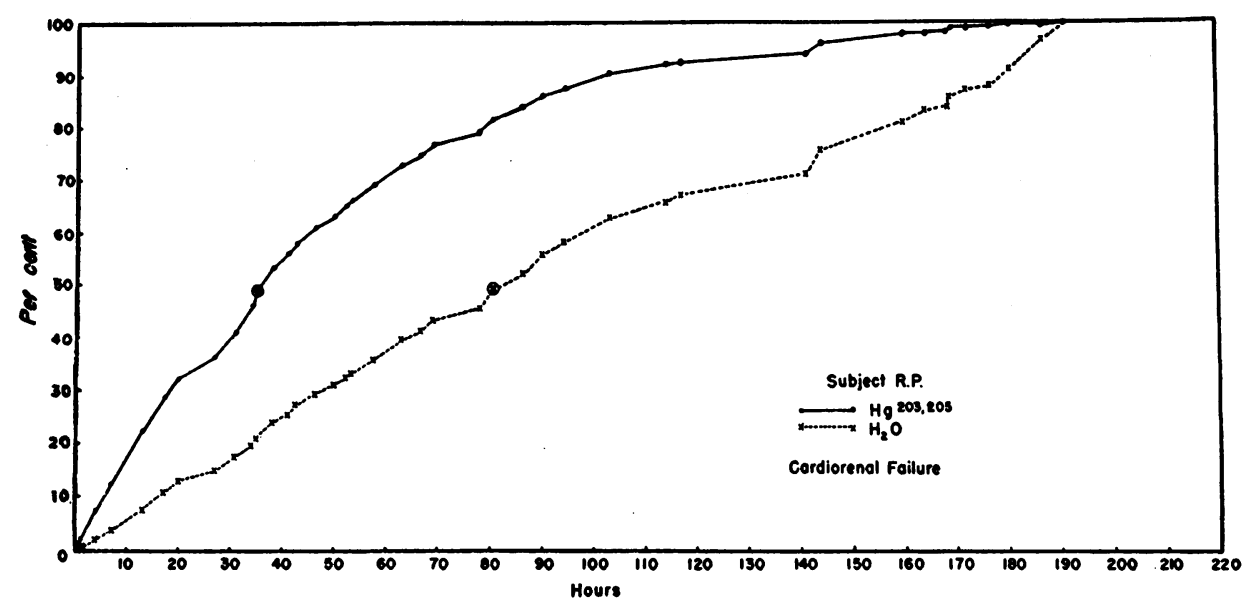

Fig. 2. The Cumulative Output of Radiomercury and Water for Subject R. P. with Congestive Heart Failure and Renal Insufficiency

The almost linear curve of water excretion indicates an absence of diuresis.

Figure 1 are partially the result of differences in rate of excretion of radiomercury, by virtue of the definition of $\mathrm{WE}_{\mathrm{i}}$.

Some differences in the slopes of the curves for water excretion are due to differences in diuretic response. There was less diuresis in the sweated than nonsweated subjects (Figure 1), and in subject R. P. (Figure 2) no diuretic response at all was noted, the curves of water excretion approaching a straight line. It should be emphasized that inasmuch as water intake was not controlled, the water curves have no volumetric quantitative value and are significant only in their temporal and percentile relationships from one group to the next.

(g) Particular subjects. Subjects with renal insufficiency excreted the radiomercury slowly; the summarized data on one such subject (R. P.) are shown in Figure 2. The $C_{1}$ value was 45 hours, $U_{E} 36$ hours, and $U_{b} 191$ hours or eight days. This subject excreted, in relatively large volumes of hyposthenuric urine, only approximately 19 per cent of the radiomercury administered (Table IV). Another subject (J. E.) with renal insufficiency and oliguria who died 112 hours after the injection excreted only 2.4 per cent of the injected radiomercury in that time. This subject had an estimated mass of edema fluid of $30.2 \mathrm{~kg}$. with a concentration of $70 \mathrm{CPM} / \mathrm{cc}$. of edema fluid or 2.1 million CPM, approximately 50 per cent of the total radiomercury administered, or 69 per cent in the extracellular fluid when the serum is also included with the edema fluid. The edema can be a storage depot of a large quantity of mercury.

\section{(2) Time-course of urinary excretion of radio- mercury}

The time-course of urinary excretion of the radiomercury was obtained by differentiating the curves shown in Figure 3. These mean curves

TABLE IV

Biologic decay periods and clinical data for two subjects with renal insufficiency

\begin{tabular}{|c|c|c|c|c|c|c|c|c|c|}
\hline \multirow{2}{*}{ Subject } & \multirow{2}{*}{$c_{i}$} & \multirow{2}{*}{$\mathrm{UE}_{4}$} & \multirow{2}{*}{$W_{4}$} & \multirow{2}{*}{$\mathrm{C}_{b}$} & \multirow{2}{*}{$U_{b}$} & \multicolumn{2}{|c|}{ Urine } & \multirow{2}{*}{ BP } & \multirow{2}{*}{ Edema } \\
\hline & & & & & & BUN & Sp. Gr. & & \\
\hline R. P. & 45 & 36 & 83 & 221 & 191 & $\begin{array}{r}235 \\
66\end{array}$ & $\begin{array}{l}1.005 \\
1.009\end{array}$ & $208 / 110$ & $4+$ \\
\hline J. E. & & & & & & 85 & 1.010 & $258 / 158$ & $4+$ \\
\hline
\end{tabular}


are essentially the same as the means of the actually observed curves for each subject. These studies, as indicated in a previous publication (6), show a concordant relationship between the concentration of radiomercury in the serum and in the urine.

The decline in rate of excretion of the radiomercury was exponential in nature, especially when the intravenous route of administration was employed, the general equation being

$$
R_{t_{2}}=R_{t_{1}} e-a\left(t_{2}-t_{1}\right),
$$

where $R_{t_{2}}=$ the rate of excretion at time $t_{2}$,

$R_{t_{1}}=$ the rate of excretion at an earlier time $t_{1}$,

$a=$ the fraction of decrease in the rate of excretion per unit of time,

e $=\log$ base.

This equation holds only after a maximum rate of excretion of the isotope has been achieved. The maximum was reached more rapidly following intravenous than intramuscular administration (Figure 3). Figures 4 and 5 show the slow rate of urinary excretion of the radiomercury for the two subjects with renal insufficiency (Figure 3 and Table IV). The maximum rate of excretion for one of the subjects (J. E.) was essentially 0.005 that of the subjects with congestive heart failure, the mean rate of excretion for this subject being less than 0.001 of the mean rate of even the subjects with congestive heart failure.

\section{(3) Rate of radiomercury clearance by the kidneys}

The rate of excretion of the radiomercury may also be expressed by the rate of renal clearance of the serum of radiomercury. The values were ob-

\section{CHANGES IN SERUM CONCENTRATION AND RATES OF EXCRETION OF MERCURY AND WATER}
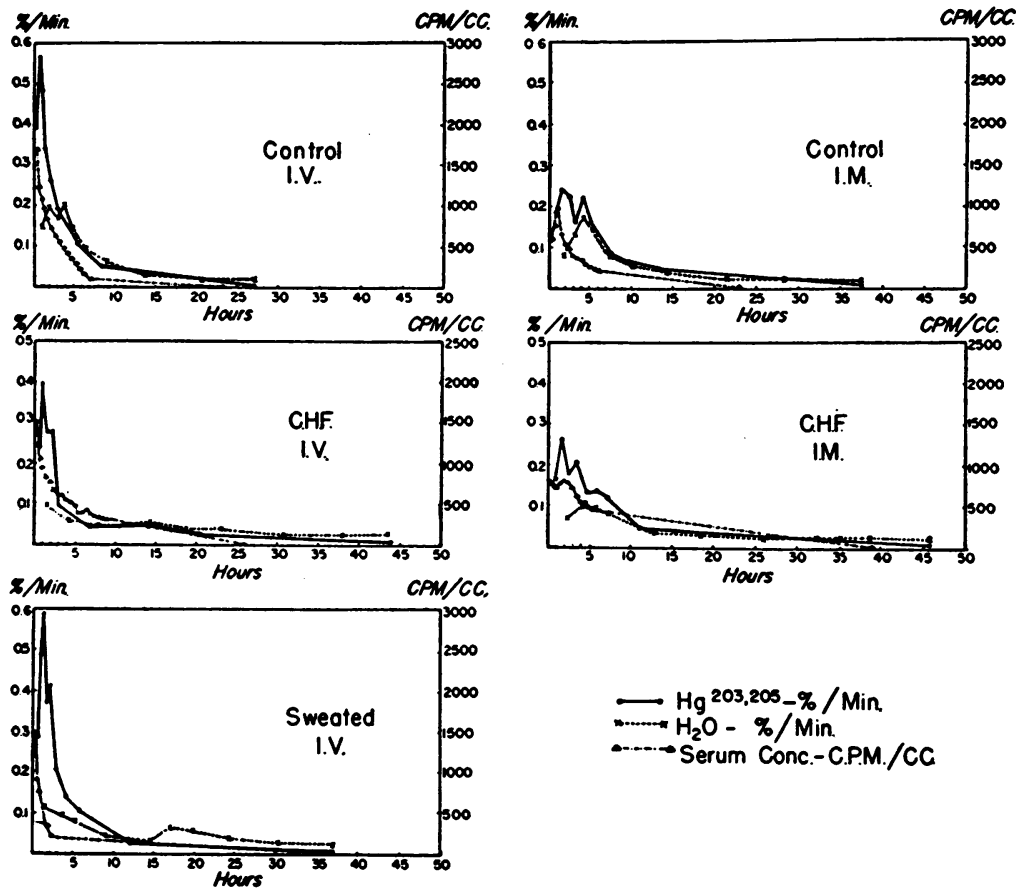

Fig. 3. The Mean Serum Concentration and Mean Rates of Excretion of Radiomercury and Water for the Five Groups Studied

The rates of urinary excretion are expressed as percentage of the total recovered mercury excreted per minute. These curves of urinary excretion are differentials of the cumulative curves of Figure 1 , or $\% / \mathrm{min} .=\mathrm{d} \% / \mathrm{dt}$, where $t$ is expressed in minutes. Each 0.1 per cent for the control group equals $8,800 \mathrm{CPM}$ of the radiomercury or $0.06864 \mathrm{mg}$. of regular mercury of the diuretic. This relationship is only approximate for the subjects with congestive heart failure. 
CHANGES IN SERUM CONCENTRATION AND RATES OF EXCRETION OF MERCURY AND WATER

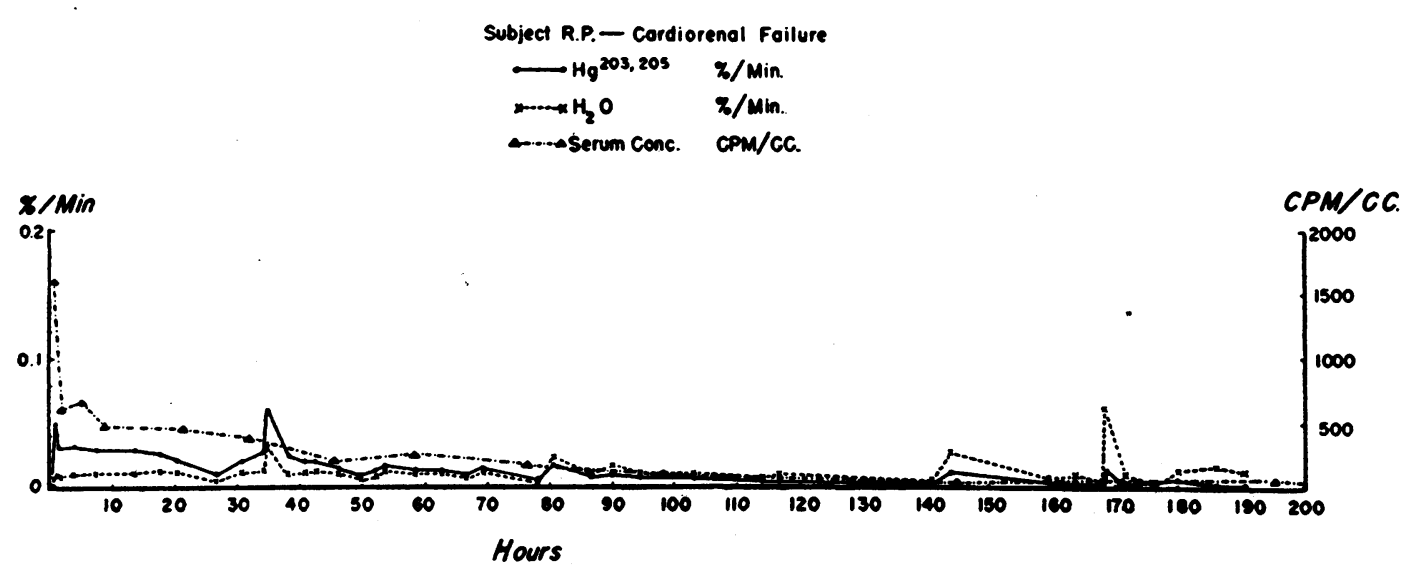

Fig. 4. The Plasma Concentration and Rates of Excretion of Radiomercury and Water for SUBJECT R. P.

Each 0.1 per cent represents approximately 1,900 CPM of the radiomercury or $0.015 \mathrm{mg}$. of the regular mercury in the diuretic.

tained by dividing the product of the urinary minute volume in cc. and urinary concentration of radiomercury in $\mathrm{CPM} / \mathrm{cc}$. by the serum concentration of radiomercury in $\mathrm{CPM} / \mathrm{cc}$., the quotient being the cc. of serum cleared of radiomercury per minute. Because of the rapid changes in concentration of serum and urine and because of high values, clearances were not calculated for the first 30 minutes after administration of the drug. It is realized that even when the plasma concentration is changing slightly, as was the case in subse- quent clearance periods, inaccuracies in the determinations exist.

Differences in rates of clearances are shown in Figure 6 for nine control subjects (mean for group $42.8 \mathrm{cc}$.), two representative subjects with chronic congestive heart failure (means 29.2 and $23.4 \mathrm{cc}$.), and one with chronic pyelonephritis (mean $22.2 \mathrm{cc}$.) all of whom received the diuretic intravenously. All subjects tended to exhibit a fairly constant rate of clearance, which conforms with the exponential rate of decline in urinary ex-

\section{CHANGES IN SERUM CONCENTRATION AND RATES OF EXCRETION OF MERCURY AND WATER}

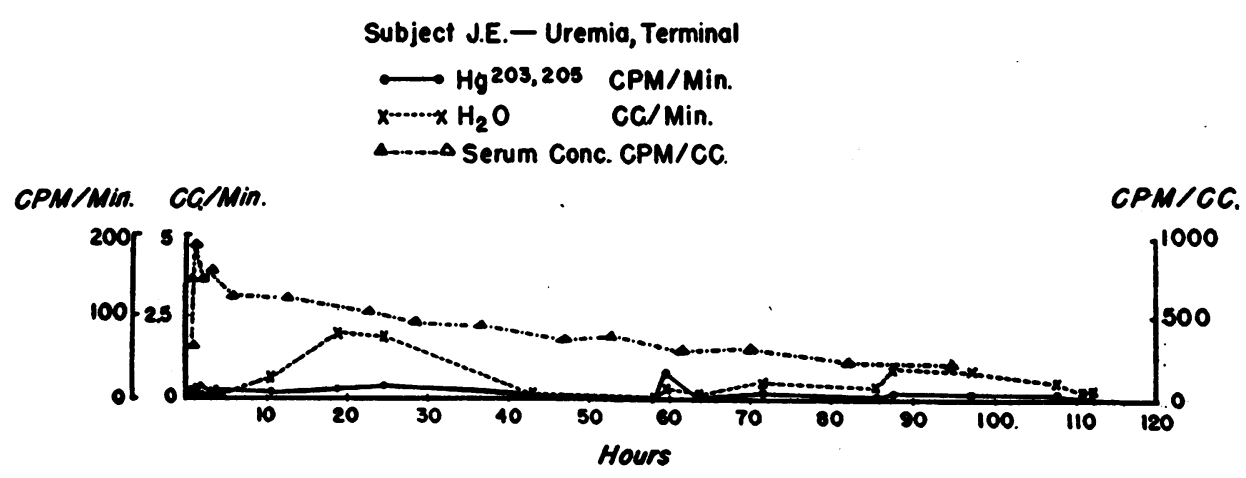

Fig. 5. The Plasma Concentration and Rates of Excretion of Radiomercury and of Water for Subject J. E., a Subject with Extreme Oliguria Who Died in Uremia

The rates of excretion are expressed as CPM/min. and cc./min., since this subject died before the urine reached background for the radiomercury. 


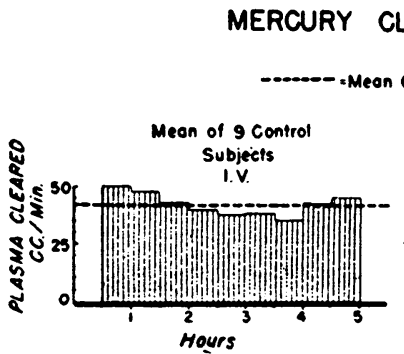

A

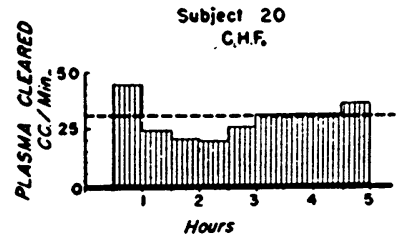

C

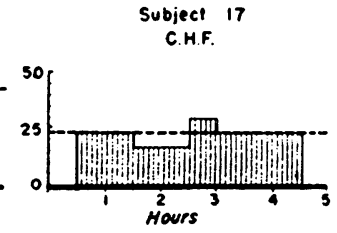

B

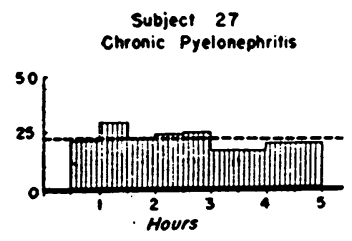

D
Fig. 6. Rates of Plasma Clearance Measured Over Consecutive Intervals of Time of 30 Minutes Each

A. Mean plasma clearance values for nine control subjects.

B. and C. Plasma clearance values for two separate subjects with chronic congestive heart failure.

D. Plasma clearance values for one subject with chronic pyelonephritis.

cretion and in serum concentration of radiomercury.

\section{DISCUSSION}

The data presented apply not only to the radiomercury but also to the stable form of the element as well. This is true for all periods of the studies, even when equilibrium of distribution or a steady state was not reached, because the quantity of mercury normally present in the body is extremely small. The mercury administered constitutes the principal mercury of the body at the time. Since this mercury is labeled with the radioactive form, measurement of the latter is a quantitative evaluation of the total mercury present in the preparation of body fluid under observation. It may be stated again that the radiometric method is a relatively simple and rapid means of measuring mercury in biologic preparations. It should be added, however, that although the measurements are simple, the physical characteristics so peculiar to mercury make errors due to volatilization readily possible.

These studies have yielded certain observations of clinical significance. For example, subjects with impaired renal function retained considerable quantities of the administered mercury even though urinary volume was relatively high. Measurable quantities of radiomercury were present in the serum of one subject for eight days, even though urinary volume was not reduced nor was there any diuretic response to the drug. Another subject with renal insufficiency excreted only about 2.5 per cent of the injected mercury in about four and one-half days. These observations indicate the need for continual evaluation of renal function to ascertain whether mercury is being retained in excessive quantities.

It is evident from the data that normal subjects excrete the mercury of the mercurial diuretic rapidly, half of it being excreted in a little over two hours whether the drug is administered intravenously or intramuscularly. On the other hand the average control subject still had mercury in the urine after 24 hours, which indicates considerable accumulation when daily doses are administered. This accumulation is even greater in the presence of disease states which reduce the rate of excretion of the mercury, such as congestive heart failure (Table II). It must also be remembered that these individual variations may be considerable and this accumulation will be even greater in certain people even though their clinical state may appear to be similar.

If a constantly elevated level of mercury in the serum is beneficial, then such an occurrence should cause no concern. If, however, accumulation of mercury at a rate of approximately 4 per cent of the injected dose per day is detrimental, then caution should be exercised and repetition of the injections should proceed at greater intervals.

The time required for the radiomercury to be "completely" excreted, or for the radiomercury to be too low in concentration to be measured in the serum, would be expected to be about ten times that required for the serum concentration to reach half-concentration after a steady state is attained. Since the regression of mercury from the serum is exponential in nature, ten times the one-half value would be $1 / 1,024$ the initial level (1000-2000 CPM/cc.) or 1 to $2 \mathrm{CPM} / \mathrm{cc}$. after about 25 hours.

The importance of the $C_{1}$ and $C_{b}$ of the radiomercury or mercury values in therapy with mer- 
curial diuretics is self-evident. Individual variations in excretion of the mercury are considerable, especially when renal disease exists. The mercury tends to be excreted more slowly when the diuretic is administered intramuscularly than when administered intravenously. This must be due in part to delay in absorption from the tissues. Other unknown factors may also be concerned with the difference.

Congestive heart failure results in delay in excretion of the mercury, as evidenced by greater $C_{\xi}$ and $C_{b}$ values for these subjects than for the control subjects. The mechanism of this delay is not known; it may be related to disturbances in the circulation itself as well as to reduction in renal function. Associated impairment of renal function or failure of diuresis to develop may result in further retention of mercury.

Acute thermal sweating for a relatively short period of time (approximately 20 to 90 minutes) resulted in a depression of the rate of water excretion but did not alter the excretion of mercury in the urine. The mechanism for this can only be conjectured.

Failure to collect 100 per cent of the injected mercury in the urine is probably due to losses of the element through other body fluids and volatilization during preparation of samples for counting (2) and to errors in measurement which occur when background levels of counts are approached.

\section{SUM MARY}

1. The mercury of a mercurial diuretic administered intramuscularly was excreted rapidly when the cardiovascular and renal functions were normal, one-half being excreted in approximately one to eight hours (mean, about three hours). The rate of excretion was slightly less rapid when the drug was administered intramuscularly than when administered intravenously.
2. Chronic congestive heart failure tended to diminish the rate of excretion, although individual variations were large. There was overlapping of the values for the control subjects and those with chronic congestive heart failure. The state and phase of the failure influenced the rate of excretion.

3. The rate of excretion of the radiomercury was considerably impaired by renal insufficiency; the degree of impairment may be great enough to result in accumulation of toxic quantities of mercury with frequent administration of the drug. The importance of this impairment in excretion during clinical therapy is evident.

4. Detailed biologic decay rates, rates of clearance, and other excretory factors are presented.

\section{BIBLIOGRAPHY}

1. Milnor, P., Burch, G., Ray, T., Threefoot, S., and Berenson, $G$., Considerations of renal, hepatic, and extremital arteriovenous differences in concentration of radiomercury of a mercurial diuretic. J. Clin. Invest., 1950, $29,72$.

2. Burch, G., Reaser, P., Ray, T., and Threefoot, S., A method of preparing biologic fluids for counting of radioelements. J. Lab. \& Clin. Med., 1950, 35, 626.

3. Kelly, F. J., Ray, C. T., Threefoot, S. A., and Burch, G. E., Influence of self-absorption, volatilization and deliquescence in counting of radioelements. J. Lab. \& Clin. Med., 1950, 35, 606.

4. Threefoot, S., Burch, G., and Reaser, P., The biologic decay periods of sodium in normal man, in patients with congestive heart failure and in patients with the nephrotic syndrome as determined by $\mathrm{Na}^{23}$ as the tracer. J. Lab. \& Clin. Med., 1949, 34, 1.

5. Burch, G. E., Threefoot, S. A., and Ray, C. T., Rates of turnover and biologic decay of chloride and chloride space in the dog determined with the long-life isotope $\mathrm{Cl}^{\text {*6. }}$. J. Lab. \& Clin. Med., 1950, $35,331$.

6. Threefoot, S. A., Ray, C. T., Burch, G. E., Cronvich, J. A., Milnor, J. P., Overman, W., and Gordon, W., Concentration-time course in the plasma of man of radiomercury introduced as a mercurial diuretic. J. Clin. Invest., 1949, 28, 661. 